\title{
ю. A. Bacehко*
}

\section{СОВЕРШЕНСТВОВАНИЕ ТЕХНОЛОГИИ ПОЛУЧЕНИЯ ИЗНОСОСТОЙКОГО ЧУГУНА}

В статье описаны результаты исследований влияния углерода, углеродного эквивалента и титана на механические свойства износостойкого чугуна. Приведены результаты статистической классификащии, позволяющей определять марку чугуна, и предложен способ оценки целесообразности применения дополнительных легирующих элементов.

ключевые слова: механические свойства, чугун, легирование.

\section{1. Введение}

Использование для легирования чугуна с повышенными требованиями к износостойкости дорогостоящих элементов не всегда оправдано с точки зрения достижения результата - повышения характеристик износостойкости чугуна. Поэтому в производстве зачастую заложены скрытые резервы ресурсосбережения. Для выявления этих резервов необходимо проведение производственных исследований, целью которых является установление зависимостей между химическим составом чугуна, в частности содержанием легирующих элементов, и его свойствами - коэффициентом износа, твердостью, пределом прочности. С другой стороны, отливки из износостойкого чугуна могут работать в различных условиях трения и, соответственно, подвергаться различным типам износа. Например, отливки из износостойкого чугуна типа лопаток бетоносмесителей, асфальтосмесителей и т. п. работают в условиях абразивного трения, а отливки лопаток дробеметных аппаратов работают преимущественно в условиях ударных нагрузок, совмещенных с абразивным трением.

Поэтому, чугун, применяемый для оливок типа дробеметных аппаратов, должен иметь более высокие показатели механической прочности. Применение же легирующих без учета специфики применения чугуна, приводит к необоснованному перерасходу легирующих элементов. Следовательно, поиск путей ресурсосбережения при производстве износостойкого чугуна должен вестись в направлении расчетов оптимального количества легирующих элементов для чугунов разных марок.

\section{2. Цель исследования}

Целью исследования является определение рационального количества легирующих элементов при получении износостойких чугунов нескольких марок, причем рациональность предполагает минимальное количество элементов, обеспечивающее достаточный эффект с точки зрения износостойкости чугуна.

\section{3. Задачи исследования}

Для достижения заданной цели были сформулированы следующие задачи:

- Исследовать связь между содержанием углерода, углеродным эквивалентом и содержанием титана и свойствами износостойкого чугуна. - Построить поверхность в пространстве названных факторов, разделяющую чугуны марок СЧ25 и СЧ30 ГОСТ1412-85.

- Предложить методы оценки целесообразности применения других легирующих элементов с точки зрения повышения твердости и износостойкости чугуна.

\section{4. Анализ литературнъх источников по проблематике исследования}

Результаты исследований влияния химического состава чугуна на его износостойкость и механические свойства приведены, например, в работах [1-4]. В данных трудах описаны результаты экспериментальных промышленных исследований, позволяющие качественно оценить влияние технологии получения чугуна на его свойства. Однако исследование возможностей количественной оценки влияния химического состава на свойства не проводилось. Это связано с отсутствием в то время методов математического моделирования, позволяющих выполнить такую оценку. Поэтому логичным развитием данной темы является применение специальных методов моделирования, в частности методов распознавания образов,

* Работа выполнена под руководством профессора кафедры литейного производства Национального технического университета «Харьковский политехнический институт» Дёмина Д. А. 
изложенных применительно к задачам металлургии сплавов и литейного производства в работах [5-7].

\section{5. Методы моделирования}

Для решения поставленных задач исследования был применен метод распознавания образов, основанный на Байесовской стратегии статистической классификации. Целью статистической классификации является построение в пространстве факторов поверхности, разделяющей чугуны марок СЧ25 и СЧЗ ГОСТ 1412-85.

В качестве переменных в факторном пространстве, позволяющих выполнить классификацию, выбираются концентрации элементов химического состава чугуна - C, Ti, а также углеродный эквивалент чугуна $C_{\text {экв}}$, являющийся оценкой влияния кремния, марганца, серы и фосфора на положение эвтектической точки на диаграмме состояния Fe-C. В пространстве переменных могут выделены два класса объектов - класс $A$, соответствующий чугуну марки СЧ30 ГОСТ1412-85, и класс $B$, соответствующий чугуну марки СЧ25 ГОСТ1412-85. При таком подходе можно рассмотреть функции условных плотностей распределения вероятностей вектора $X$ для классов $A$ и $B-p_{A}(X)$ и $p_{B}(X)$. Априорные вероятности $P(A)$ и $P(B)$ принадлежности любого объекта к классу $A$ и $B$ соответственно могут быть оценены непосредственно на основе производственных данных по выплавке чугунов разных марок и соответственно выбранных способов управления процессами плавки.

Закон распределения содержания элементов химического состава чугуна можно считать нормальным, $p_{A}(X)$ и $p_{B}(X)-$ плотности вероятности нормальных законов распределения вектора $X$ для классов $A$ и $B$ соответственно.

Для примера на рис. 1 показана гистограмма распределения содержания титана в чугуне.

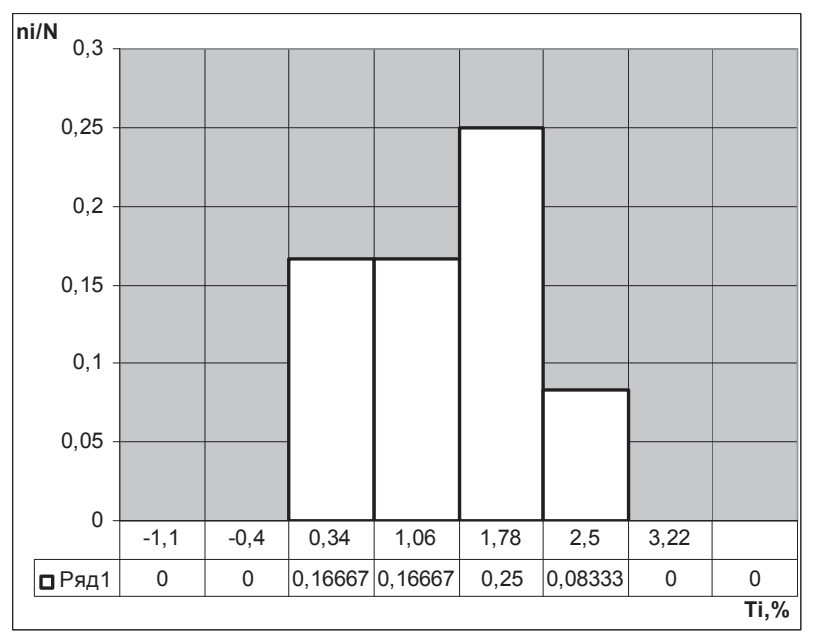

Pис. 1. Гистограмма распределения содержания титана в чугуне
Элемент выборки экспериментальных данных приведен в табл. 1 [8].

Таблица 1

Экспериментальные данные

\begin{tabular}{|c|c|c|c|c|c|c|}
\hline \multirow[b]{2}{*}{$\begin{array}{c}\text { Тип белого } \\
\text { чугуна }\end{array}$} & \multicolumn{4}{|c|}{ Химический состав в \% } & \multirow{2}{*}{ 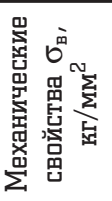 } & \multirow{2}{*}{ 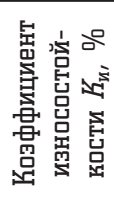 } \\
\hline & ᄃ & $5 i$ & Mn & $\mathrm{Ti}$ & & \\
\hline \multirow{3}{*}{$\begin{array}{l}\text { Нелегиро- } \\
\text { ванный }\end{array}$} & 2,17 & 1,27 & 0,89 & - & 41,7 & 3,38 \\
\hline & 2,68 & 1,3 & 0,96 & - & 27,5 & 5 \\
\hline & 3,3 & 1,28 & 1,07 & - & 28 & 4,05 \\
\hline \multirow{13}{*}{$\begin{array}{l}\text { Легиро- } \\
\text { ванный } \\
\text { титаном }\end{array}$} & 2,25 & 1,31 & 0,95 & 0,32 & 45,2 & 6,2 \\
\hline & 2,37 & 1,4 & 0,99 & 0,63 & 44,4 & 11,54 \\
\hline & 2,26 & 1,03 & 1,01 & 0,94 & 38,8 & 9,57 \\
\hline & 2,21 & 1,53 & 0,95 & 1,69 & 30 & 9,44 \\
\hline & 2,4 & 1,16 & 1,14 & 2,1 & 31,1 & 10,8 \\
\hline & 2,68 & 1,08 & 0,6 & 0,37 & 28,4 & 8,19 \\
\hline & 2,69 & 0,93 & 1,07 & 0,75 & 27,4 & 9,7 \\
\hline & 2,53 & 1,5 & 1,02 & 1,26 & 36,2 & 12,27 \\
\hline & 2,73 & 1,1 & 1,21 & 2,94 & 27,9 & 9,7 \\
\hline & 3,13 & 1,6 & 0,78 & 0,28 & 20,1 & 8,26 \\
\hline & 3,34 & 1,4 & 1,1 & 0,73 & 24,5 & 11,07 \\
\hline & 3,24 & 1,4 & 0,98 & 1,54 & 33,9 & 9,19 \\
\hline & 3,34 & 1,72 & 0,98 & 2,5 & 17,8 & 8,07 \\
\hline
\end{tabular}

Если $m^{A}$ и $m^{B}-$ математические ожидания вектора $X$ для классов $A$ и $B$, и ковариационные матрицы распределения вектора $X$ для классов $A$ и $B$ равны $\left(\operatorname{cov}^{A}(X)=\operatorname{cov}^{B}(X)\right)$, плотности распределения вероятностей $p_{A}(X)$ и $p_{B}(X)$ могут быть представлены в виде:

$$
\begin{aligned}
& p_{A}(X)=k e^{\left(-\frac{1}{2}\left(x-m^{A}\right)^{\prime} \operatorname{cov}^{-1}(x)\left(x-m^{A}\right)\right)} ; \\
& p_{B}(X)=k e^{\left(-\frac{1}{2}\left(x-m^{B}\right)^{\prime} \operatorname{cov}^{-1}(x)\left(x-m^{B}\right)\right)},
\end{aligned}
$$

где $k-$ постоянный множитель.

Условные вероятности принадлежности $j$-го объекта к классу $A$ и $B$, согласно теореме Байеса, определяются по формулам:

$$
\begin{aligned}
& P\left(A \mid x^{j}\right)=\frac{P(A) p_{A}\left(x^{j}\right)}{P(A) p_{A}\left(x^{j}\right)+P(B) p_{B}\left(x^{j}\right)} ; \\
& P\left(B \mid x^{j}\right)=\frac{P(B) p_{B}\left(x^{j}\right)}{P(A) p_{A}\left(x^{j}\right)+P(B) p_{B}\left(x^{j}\right)} .
\end{aligned}
$$

Объект $x^{j}$ может быть отнесен к тому классу, которому соответствует большая условная вероятность: 


$$
\begin{aligned}
& x^{j} \in A \text { если } P\left(A \mid x^{j}\right) \geq P\left(B \mid x^{j}\right) ; \\
& x^{j} \in B \text { если } P\left(A \mid x^{j}\right)<P\left(B \mid x^{j}\right) .
\end{aligned}
$$

Следовательно, классификация объекта $x^{j}$ осуществляется в зависимости от величины функции:

$$
L\left(x^{j}\right)=\frac{P(A) p_{A}\left(x^{j}\right)}{P(B) p_{B}\left(x^{j}\right)}=\frac{P(A)}{P(B)} l\left(x^{j}\right),
$$

где $l\left(x^{j}\right)-$ отношение правдоподобия.

Следовательно, классифицирующее правило можно записать в виде:

$$
\begin{aligned}
& x^{j} \in A \text { если } L\left(\mid x^{j}\right) \geq 1, \\
& x^{j} \in B \text { если } L\left(\mid x^{j}\right)<1 .
\end{aligned}
$$

Задавая граничное значение $L\left(x^{j}\right)=1$, классифицирующее правило может быть представлено в виде:

$$
\begin{aligned}
& x^{j} \in A \text { если } L\left(x^{j}\right)=\frac{P(A) k e^{\left(-\frac{1}{2}\left(x-m^{A}\right)^{\prime} \operatorname{cov}^{-1}(x)\left(x-m^{A}\right)\right)}}{P(B) k e^{\left(-\frac{1}{2}\left(x-m^{B}\right)^{\prime} \operatorname{cov}^{-1}(x)\left(x-m^{B}\right)\right)}} \geq 1 ; \\
& x^{j} \in B \text { если } L\left(x^{j}\right)=\frac{P(A) k e^{\left(-\frac{1}{2}\left(x-m^{A}\right)^{\prime} \operatorname{cov}^{-1}(x)\left(x-m^{A}\right)\right)}}{P(B) k e^{\left(-\frac{1}{2}\left(x-m^{B}\right)^{\prime} \operatorname{cov}^{-1}(x)\left(x-m^{B}\right)\right)}}<1 .
\end{aligned}
$$

где $F\left(x^{j}\right)$ - дискриминантная функция, определяемая по уравнению (8), а $y_{0}-$ пороговое значение дискриминантной функции.

$$
\begin{aligned}
& F(x)=x^{\prime} \operatorname{cov}^{-1}(x)\left(m^{A}-m^{B}\right)= \\
& =\frac{1}{2}\left(m^{A}+m^{B}\right)^{\prime} \operatorname{cov}^{-1}(x)\left(m^{A}-m^{B}\right)-\ln \frac{P(A)}{P(B)} .
\end{aligned}
$$

Координатами вектора $X$ выбираются $C_{\text {экв }}\left(x_{1}\right)$, содержания $\operatorname{Ti}\left(x_{2}\right), C\left(x_{3}\right)$.

Полученное классифицирующее правило, позволяющее относить объект к одному из классов (класс $A-$ чугуны марок СЧЗ3, класс $B-$ чугуны марок СЧ25), имеет вид:

$$
\begin{aligned}
& x^{j} \in A \text { если }\left[11,857 x_{1}+1,499 x_{2}-18,756 x_{3} \geq(-12,853)\right], \\
& x^{j} \in B \text { если }\left[11,857 x_{1}+1,499 x_{2}-18,756 x_{3}<(-12,853)\right] .
\end{aligned}
$$

На рис. 2 представлены гистограммы распределения для классов $A$ и $B$.

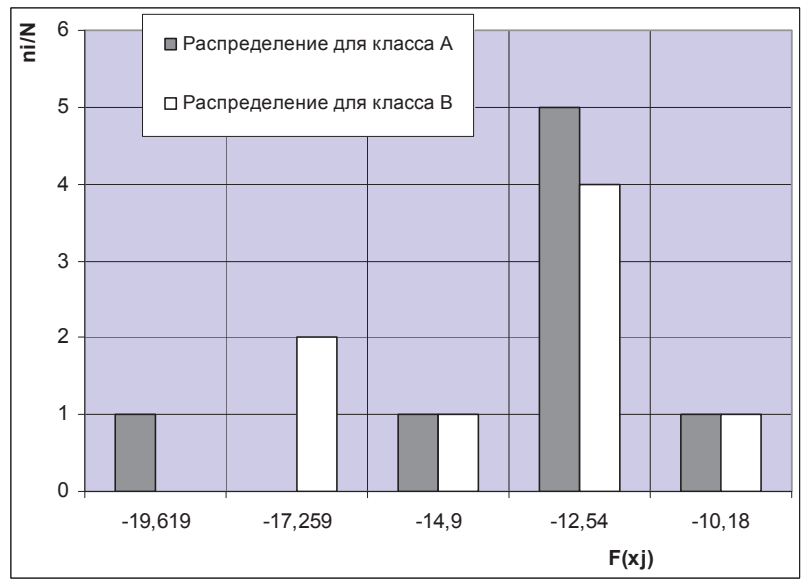

Pис. 2. Гистограммы распределения значения дискриминантной функции для классов $A$ и $B$

Из рис. 2 следует, что имеет место область перекрытия гистограмм, площадь которой позволяет судить о возможной неточности принятия решений о принадлежности чугуна к марке СЧ25 и СЧ30 соответственно. Тем не менее, полученное классифицирующее правило (9) позволяет сделать предварительную оценку марки выплавляемого чугуна и использовать полученное решение для выбора рационального количества титана с точки зрения влияния на коэффициент износостойкости в зависимости от выплавляемой марки чугуна.

Для этого необходимо построение математической модели, связывающей углеродный эквивалент, содержание углерода и содержание титана в чугуне с коэффициентом износостойкости. Такая модель строится с помощью метода наименьших квадратов [9], и позволяет решить задачу оптимизации химического состава [10-11] и исследование поверхности отклика [12] для выбора оптимального количества титана для легирования чугуна в зависимости от содержания углерода в нем и углеродного эквивалента. Полученные при этом решения должны закладываться в систему управления электроплавкой чугуна [13].

Целесообразность использования других легирующих элементов для повышения износостойкости чугуна должна проверяться следующим образом. Имея математическую модель, связывающую углеродный эквивалент, содержание углерода и содержание титана в чугуне с коэффициентом износостойкости, и проведя малую серию промышленных экспериментов по (9) легированию чугуна дополнительным элементом, проводится дисперсионный 
анализ [14]. Задача, в первую очередь, сводится к тому, чтобы установить:

- значимо ли влияние вводимого элемента на повышение износостойкости чугуна;

- если влияние значимо, начиная с какого уровня этого фактора (количества вводимого элемента) выборочные средние результаты значимо различаются между собой.

Результаты производственных данных о химическом составе чугуна группируются в виде таблицы, в которой отдельным столбцам соответствуют результаты параллельных измерений на каждом уровне изучаемого фактора, а в строках располагаются выборки результатов с одинаковым порядковым номером, но на разных уровнях фактора.

Алгоритм процедуры заключается в следующем. Для выбранной марки чугуна, характеризуемой углеродным эквивалентом с содержанием углерода, рассчитываются групповые средние содержания $\mathrm{Ti}$ и вводимого элемента (например, бора $B$ ):

$$
\begin{array}{r}
T i_{j, \text { ср, гр }}=\frac{\sum_{i=1}^{n} T i_{j, i}}{n}, \\
B_{j, \text { ср, гр }}=\frac{\sum_{i=1}^{n} B_{j, i}}{n},
\end{array}
$$

где $T i_{j, \text { ср,гр }}, B_{i j, \text { ср,гр }}-$ среднегрупповые значения концентрации титана и бора в чугуне, $\%, n-$ число параллельных результатов химического анализа, $T i_{j, i}, B_{i j, i}-$ концентрации титана и бора в каждом из параллельных результатов для заданной марки чугуна, \%.

Рассчитывается сумма квадратов отклонений каждого из результатов анализа от общего среднего. Общая сумма квадратов определяется суммированием всех $n \times k$ квадратов отклонений отдельных результатов:

$$
\begin{aligned}
& \sum \text { общ }=\sum_{j=1}^{k} \sum_{i=1}^{n}\left(T i_{j, i}-T i_{\mathrm{cp}}\right)^{2}, \\
& \sum \text { общ }=\sum_{j=1}^{k} \sum_{i=1}^{n}\left(B_{j, i}-B_{\mathrm{cp}}\right),
\end{aligned}
$$

где $k$ - число уровней, $T i_{\text {ср }}, B_{\text {ср }}-$ общее среднее содержание титана и бора в чугуне, \%, определяемое по формулам:

$$
T i_{\mathrm{cp}}=\frac{\left(\sum_{j=1}^{k} T i_{j, \text { ср, гр }}\right)}{k},
$$

$$
B_{\mathrm{cp}}=\frac{\left(\sum_{j=1}^{k} B_{j, \text { ср, гр })}\right.}{k} .
$$

Вычисляется факторная сумма как $n-$ кратная сумма квадратов отклонений к групповых средних

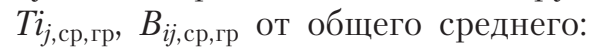

$$
\begin{aligned}
& \sum \text { факт }=n \sum_{J=1}^{K}\left(T i_{j, \text { ср, гр }}-T i_{\mathrm{cp}}\right), \\
& \sum \text { факт }=n \sum_{J=1}^{K}\left(B_{j, \text { ср, гр }}-B_{\mathrm{cp}}\right) .
\end{aligned}
$$

Факторная сумма отражает влияние фактора на результаты измерений, так как учитывает рассеяние результатов около общего среднего при действии выбранного фактора. В отличие от нее, остаточная сумма учитывает рассеяние результатов химического анализа содержания титана и бора около группового среднего $T i_{j, \text { ср,гр }}, B_{i j, \text { ср,гр }}$ при постоянном уровне фактора. Определяется остаточная сумма путем последовательного сложения частных сумм квадратов отклонений по всем группам, и вычисляются соответствующие им дисперсии:

- факторная дисперсия с числом степеней сво-

боды $(k-1)$;

- остаточная дисперсия с числом степеней свободы $(n k-k)$.

Найденные значения дисперсий сравниваются с помощью $F$ - критерия Фишера. Если выполняется условие для заданного уровня значимости и числа степеней свободы, то делается вывод о том, что выбранный фактор влияет на результат анализа. В противном случае влияние фактора считается несущественным.

Если установлено, что выбранный фактор, является значимым, то определяется уровень, начиная с которого проявляется его влияние.

\section{7. Выводы}

1. Показана эффективность применения метода статистической классификации для установления связи между содержанием углерода, углеродным эквивалентом и содержанием титана и свойствами износостойкого чугуна.

2. Построена поверхность в пространстве $C_{\text {экв}}$-С-Тi, разделяющая чугуны марок СЧ25 и СЧЗ ГОСТ1412-85.

3. Предложено для оценки целесообразности применения других легирующих элементов с точки зрения повышения твердости и износостойкости чугуна применять дисперсионный анализ. 


\section{Литература}

1. Кривошеев А. Е. Высокотвердий износостойкий отбеленный легированный чугун [Текст] / А. Е. Кривошеев, Н. П. Котешов // Литейное производство. - 1967. - № 9.

2. Китайгора Н. И. Стойкость высокохромистых чугунов в условиях ударно-абразивного износа [Текст] / Н. И. Китайгора // Литейное производство. - 1972. - № 2.

3. Емелюшин А. Н. Влияние титана и бора на износостойкость чугуна предназначенного для механической обработки неметаллических материалов инструмента из хромистых чугунов [Текст] / А. Н. Емелюшин // Известия высших учебных заведений. Черная металлургия. -2000 . - № 2.

4. Конторов Б. М. Износостойкие белые чугуны, легированные бором и титаном [Текст] / Б. М. Конторов, Н. М. Кунин // Литейное производство. - 1960. - № 4 .

5. Дёмин Д. А. Диагностика технологического процесса. Руководство для технолога [Текст] / Д. А. Дёмин. - Восточно-Европейский журнал передовых технологий. - Х. : Технологический Центр. - 2005. - № 5/1(17). - С. 29-40.

6. Дёмин Д. А. Идентификация чугуна для определения рациональных режимов легирования [Текст] / Д. А. Дёмин, А. Б. Божко, А. В. Зрайченко, А. Г. Некрасов // Східно-Свропейський журнал передових технологій. - Харків : Технологічний Центр. - 2006. - № 4/1(22). - С. 29-32.

7. Дёмин Д. А. Принятие решений в процессе управления электроплавкой с учетом факторов нестабильности технологического процесса [Текст] / Д. А. Дёмин // Вісник національного технічного університету «ХПІ». - Харків : НТУ «ХПІ». 2010. - № 17. - С. 67-72.

8. Васенко Ю. А. Моделирование износостойкости чугуна, легированного титаном, по данным пассивного эксперимента [Текст] / Ю. А. Васенко // Технологический аудит и резервы производства. - Х. : Технологический Центр. - 2011. № $2 / 2$. - C. $3-8$.

9. Дёмин Д. А. Обработка экспериментальных данных и построение математической модели технологического процесса методом наименьших квадратов (МНК) [Текст] / Д. А. Дёмин // Восточно-Европейский журнал передовых технологий. - Х. : Технологический Центр. - 2006. № $3 / 1$. - C. 47-50.

10. Дёмин Д. А. Оптимизация технологического процесса в цехе предприятия [Текст] / Д. А. Дёмин // Восточно-Европейский журнал передовых технологий. - Х. : Технологический Центр. - 2005. № 6. - С. 48-59.

11. Коваленко Б. П. Оптимизация состава холоднотвердеющих смесей (ХТС) с пропиленкарбонатом [Текст] / Б. П. Коваленко, Д. А. Дёмин,
А. Б. Божко // Восточно-Европейский журнал передовых технологий. - Х. : Технологический Центр. - 2006. - № 6. - С. 59-61.

12. Дёмин Д. А. Оптимизация технологических режимов [Текст] / Д. А. Дёмин // Восточно-Европейский журнал передовых технологий. - Х. : Технологический Центр. - 2006. - № 2/1(20). C. $32-35$.

13. Дёмин Д. А. Синтез систем управления технологическими процессами електродуговой плавки чугуна [Текст] / Д. А. Дёмин // Восточно-Европейский журнал передовых технологий. - Х. : Технологический Центр. - 2012. - № 2/10(56). C. 4-9.

14. Дьомін Д. О. Деякі аспекти управління якістю чавуна з пластинчастим графітом [Текст] : автореф. дис. ... канд. техн. наук: 05.16.04 / Д. О. Дьомін; [Харківський політехнічний інститут ХПІ] .X., 1995. -24 c.

\section{УДОСКОНАЛЕННЯ ТЕХНОЛОГІї ОТРИМАННЯ ЗНОСОСТЙКОГО ЧАВУНУ}

\section{Ю. О. Bacerko}

У статті описані результати досліджень впливу вуглецю, вуглецевого еквівалента і титану на механічні властивості зносостійкого чавуну. Наведені результати статистичної класифікації, що дозволяють визначати марку чавуну, і запропоновано спосіб оцінки доцільності застосування додаткових легуючих елементів.

Ключові слова: механічні властивості, чавун, легуваннн.

Юрій Олексійович Васенко, магістрант кафедри ливарного виробництва Національного технічного університету «Хар ківський політехнічний інститут»

\section{TECHNOLOGY FOR IMPROVED WEAR IRON}

\section{Y. Vasenko}

The article describes the results of studies of the effect of carbon, carbon equivalent and titanium on mechanical properties of wear-resistant cast iron. The results of statistical classification, which allows to determine the grade of iron, and a method for assessing the feasibility of additional alloying elements.

Keywords: mechanical properties, cast iron, alloying.

Yuriy Vasenko, student of foundry, National Technical University «Kharkiv Polytechnic Institute»

\section{Адрес для переписки:}

61002, г. Харьков, ул. Фрунзе, 21

Национальный технический университет

«Харьковский политехнический институт»

Кафедра «Литейное производства»

E-mail: nauka@jet.com.ua 